context, the cumulative impacts of fire and timber harvesting are worrying. It has already been shown that clear-cut harvesting has considerably altered the ageclass representation of forests at the landscape level by diminishing the number of stands older than the length of a typical harvest rotation (Bergeron et al., 2006; Cyr et al., 2009). Excessive use of even-aged management, therefore, erodes ecological resilience by reducing ecosystem variability in time and space (Drever et al., 2006), and this erosion will be exacerbated by the predicted increase in fire with future climate warming (Bergeron et al., in press).

\section{Data}

Charcoal data is available from the Global Charcoal Database http://www.bridge. bris.ac.uk/projects/QUEST_IGBP_Global_ Palaeofire_WG/index.html

\section{References}

Ali, A.A., Carcaillet, C. and Bergeron, Y., 2009: Long-term fire frequency variability in the eastern Canadian boreal forest: the influences of climate vs. local factors, Global Change Biology, 15: 1230-1241.

Bergeron, Y., Cyr, D., Girardin, M.P. and Carcaillet, C., in press: Will climate change drive $21^{\text {st }}$ century burn rates in Canadian boreal forests outside of natural variability: collating global climate model experiments with sedimentary charcoal data, International Journal of Wildland Fire.

Cyr, D., Gauthier, S., Bergeron, Y. and Carcaillet, C., 2009: Forest management is driving the eastern part of North American boreal forest outside its natural range of fire-interval variability, Frontiers in Ecology and the Environment, 7: 519-524.

Girardin, M.P., Ali, A.A., Carcaillet, C., Mudelsee, M., Drobyshev, I., Hély, C. and Bergeron Y., 2009: Heterogeneous response of circumboreal wildfire risk to climate change since the early 1900s, Global Change Biology, 15: 2751-2769.

Hély, C., Girardin, M.P., Ali, A.A., Carcaillet, C., Brewer, S. and Bergeron, Y., 2010. Eastern boreal North American wildfire risk of the past 7000 years: a model-data comparison, Geophysical Research Letters, 37: L14709, doi:10.1029/2010GL043706.

\title{
Fire and climate variation in western North America from fire-scar and tree-ring networks
}

\begin{abstract}
Donald A. Falk ${ }^{1,4}$, E.K. Heyerdahl ${ }^{2}$, P.M. Brown ${ }^{3}$, T.W. Swetnam ${ }^{4}$, E.K. Sutherland ${ }^{5}$, Z. Gedalof ${ }^{6}$, L. Yocom ${ }^{7}$ and T.J. Brown ${ }^{8}$
${ }^{1}$ School of Natural Resources and the Environment, The University of Arizona, Tucson, USA: dafalk@u.arizona.edu

2Fire Science Laboratory, Rocky Mountain Research Station, US Forest Service, Missoula, USA; ${ }^{2}$ Rocky Mountain Tree-Ring Research, Inc., Fort Collins, USA; ${ }^{4}$ Laboratory of Tree-Ring Research, The University of Arizona, Tucson, USA; ${ }^{5}$ Forestry Sciences Laboratory, Rocky Mountain Research Station, US Forest Service, Missoula, USA; ${ }^{6}$ Climate and Ecosystem Dynamics Research Laboratory, Department of Geography, University of Guelph, Canada; ${ }^{7}$ School of Forestry, Northern Arizona University, Flagstaff, USA; ${ }^{\circ}$ Western Regional Climate Center, Desert Research Institute, Reno, USA

\section{Multi-scale fire-scar networks in western North America open new lines of inquiry into fire as an ecosystem process and reveal interactions of top-down and bottom-up regulatory factors across scales of space and time.}

Fire regimes (i.e., the pattern, frequency and intensity of fire in a region) reflect a complex interplay of bottom-up and topdown controls (Lertzman et al., 1998; Mc Kenzie et al., in press). Bottom-up controls include local variations in topographic, fuel and weather factors at the time of a burn (e.g., fuel moisture and continuity, ignition density and local wind and humidity patterns). Bottom-up regulation is manifest as fine-scale spatial and temporal heterogeneity in fire behavior and effects within landscapes subject to the same general climate. Examples include variation in fuel consumption, tree mortality and soil effects, which create complex burn severity legacies that can influence subsequent fires (Collins and Stephens, 2008; Scholl and Taylor, 2010).

Climate is the primary top-down control of fire regimes, acting largely through interannual regulation of biomass production, fuel moisture and regional ignition patterns, and control of the geographic distribution of biomes. Top-down regulation leads to spatial and temporal synchrony in fire occurrence beyond scales at which individual fires are likely to spread.

Recent scientific publications and interest in fire climatology on centennial to multimillenial timescales has expanded our understanding of the interplay of bottom-up and top-down regulation of forest fire regimes (Falk et al., 2007; Swetnam

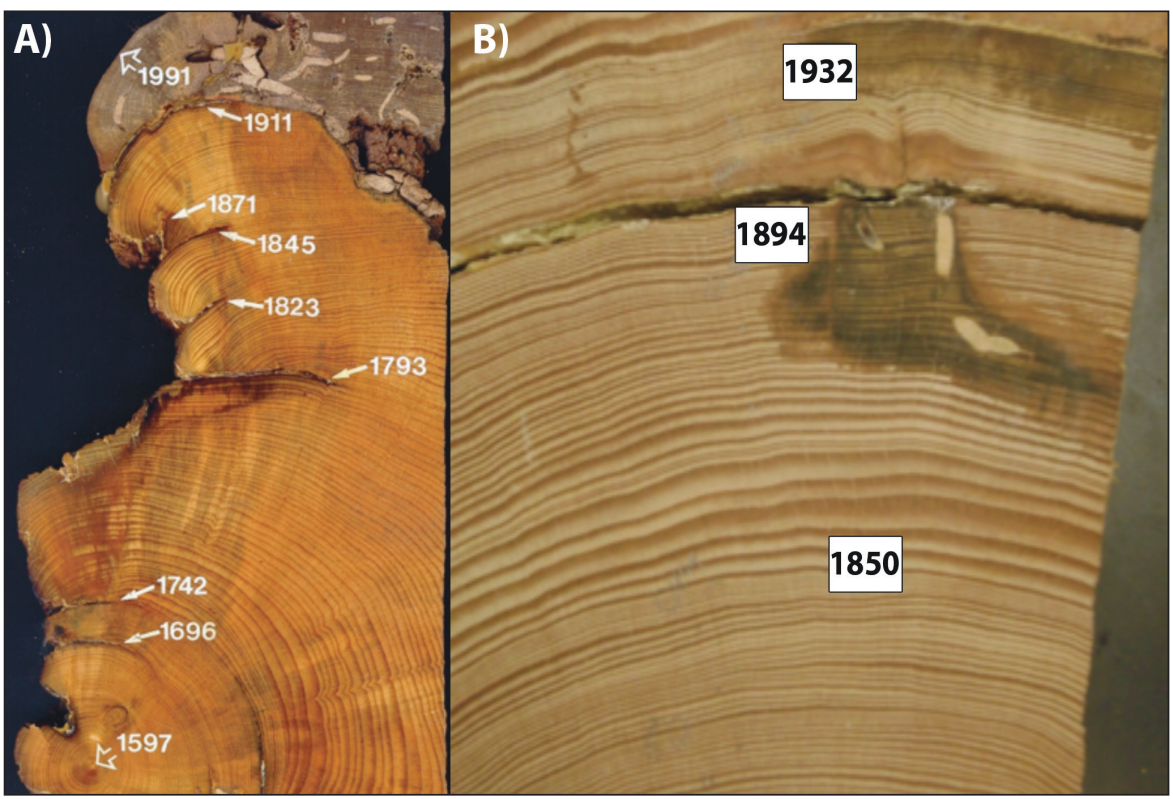

Figure 1: Tree-ring evidence of fires includes cross-dated fire scars and abrupt increases or decreases in ring width A) Cross-dated Pinus ponderosa fire-scarred sample (Photo: P. Brown, Rocky Mountain Tree-Ring Research). B Bigcone Douglas-fir (Pseudotsuga macrocarpa) sample from Los Padres National Forest, USA, exhibiting growth anomalies following an 1850 wildfire, a buried fire scar dated to an 1894 wildfire, and both a fire scar and growth change from the 1932 Matilija Fire (Photo: K. Lombardo, Laboratory of Tree-Ring Research, University of Arizona).

and Anderson, 2008; Conedera et al., 2009; Whitlock et al., 2010). New understanding of broad-scale ocean-atmosphere oscillations (e.g., El Niño-Southern Oscillation (ENSO), Pacific Decadal Oscillation (PDO), Atlantic Multidecadal Oscillation (AMO)) and their influence on regional climate, has clarified the mechanisms that synchronize fires across regions (Schoennagel et al., 2005; Kitzberger et al., 2007; Heyerdahl et al., 2008; Trouet et al., 2010).
Contemporary human influences on fire regimes (including fire suppression, forest management, altered landscape configurations and the spread of non-native species) complicate the analysis of what drives fire regimes. Modern data cover a limited time frame and thus cannot capture longer-term variation in fire regimes driven by climate variability and ecosystem succession. Paleoecological data are essential to understand interactions of 
vegetation, climate and people in past and current ecosystems; to create a multiscale "pyrogeography" for coupled natural-human systems.

\section{Development of the North American fire history network}

Fire regimes can be reconstructed from fire scars evident in tree rings, abrupt changes in tree-ring width, tree recruitment and mortality (from tree-age data), historical records and landscape analysis of forest structure (Fig. 1). Fire scars have been used since the 1930s to provide local fire chronologies but in the last 20 years the temporal and spatial coverage of the fire-scar record has expanded dramatically. In western North America, it now includes networks of 100 s to 1000 s of trees sampled across 100 s to 10,000 s of hectares, spanning centuries to millennia.

\section{New insights from fire history networks}

The extensive North American fire-history network yields new avenues for understanding past fire dynamics across multiple scales. Spatial patterns of annual fire occurrence are now being mapped at multiple scales (Swetnam et al., in press). At fine scales, patterns of historical fire occurrence are reconstructed using spatially-distributed sampling designs (Fig. 2). Such studies encompass fire perimeters and thus estimate fire size, as well as reveal the landscape heterogeneity and interactions between successive fires that are characteristic of bottom-up regulation (Heyerdahl et al., 2001; Hessl et al., 2007; Farris et al., 2010; Scholl and Taylor, 2010).

At larger spatial and temporal scales, synchronous fire occurrence captured in networks of fire-history chronologies reveals the entrainment of fire regimes by droughts, pluvials and other expressions of regional climate variability (Fig. 3). Fire-history networks, for example, have revealed the signature of interannual to multidecadal climate modes (especially ENSO, PDO and AMO) in regional fire regimes across western North America (Kitzberger et al., 2007; Morgan et al., 2008; Trouet et al., 2010).

Recent studies also incorporate annually resolved tree demographic data (recruitment and mortality) to infer spatial variability in fire behavior (e.g., crown vs. surface fire) and show how patterns have varied between historical and current forests (Brown et al., 2008). For example, tree-age data from a 240 -a study on southern Colorado ponderosa pine (Pinus ponderosa) found that episodic recruitment occurred largely during periods

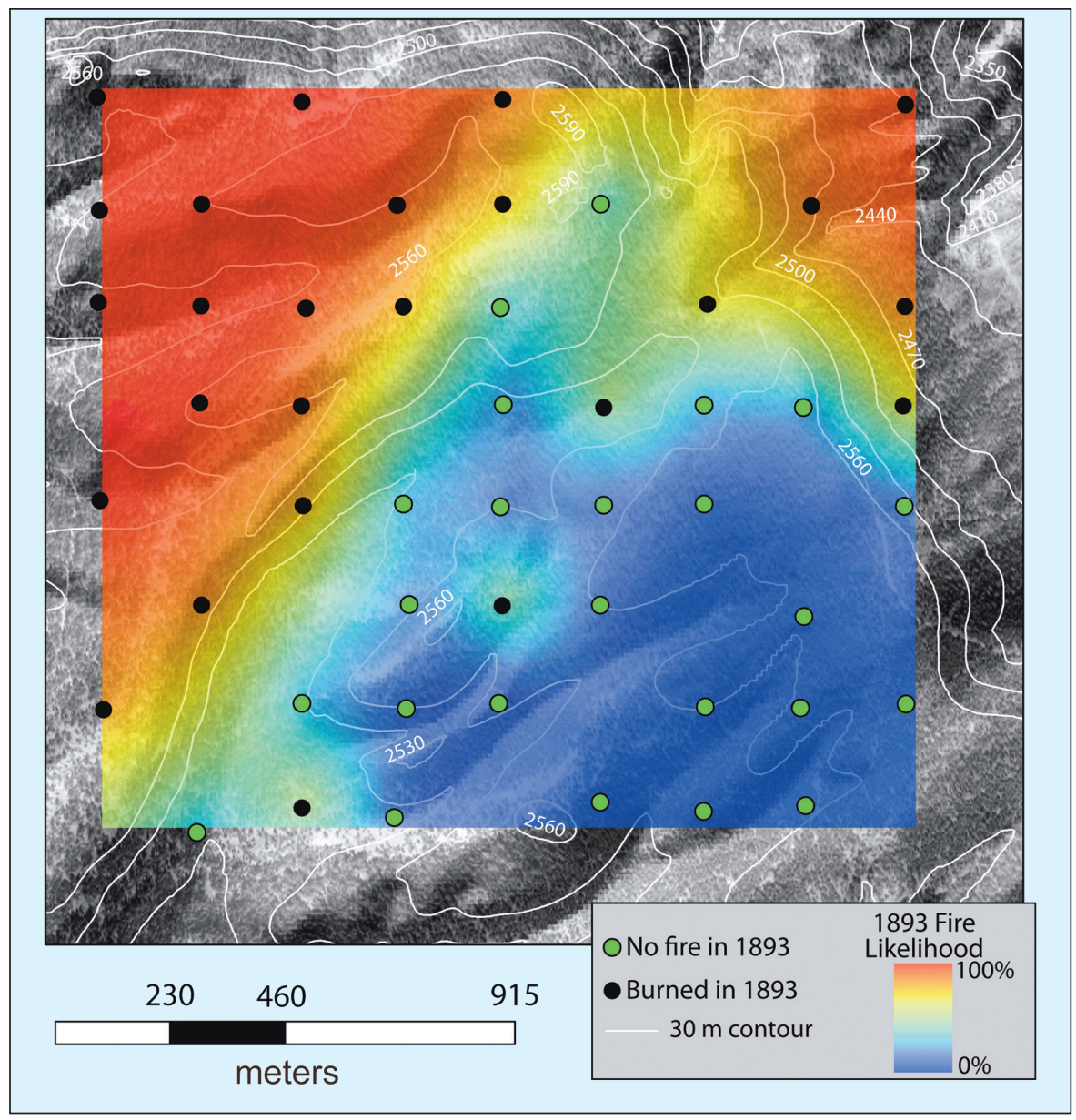

Figure 2: Spatial pattern in fire occurrence at Monument Canyon Research Natural Area, USA, reconstructed from AD 1893 fire scar data using a $200 \mathrm{~m}$ gridded sampling design (Swetnam et al., in press). Circles indicate the locations of fire scar sample plots with multiple trees sampled over a 0.5-ha area. Inverse-distance weighting was used to spatially interpolate occurrence of fire in AD 1893 using the nearest neighbors of each plot. Red areas indicates a high (>89\%) probability of fire occurrence based on presence of fire at surrounding plots; green - blue areas indicate low probability (<20\%) of fire occurrence in that year. Spatial reconstruction can reveal bottom-up fire controls that modify fire spread, and leave a complex post-fire legacy. Data from Falk and Swetnam, 2003; Map by T.L. Swetnam.

when regional climate was less favorable to fire, permitting higher survivorship of seedlings (Brown and Wu, 2005). Combined with demographic data, fire-history networks elucidate the complex environment/climate/vegetation interactions that regulate both fire regimes and ecosystem responses at multiple scales of space and time (Brown, 2006; Margolis and Balmat, 2009).

\section{Fire scar networks and research in Canada and Mexico}

The complex fire regimes of western Canada require multi-proxy approaches to reconstructing fire history, including firescar chronologies, charcoal in lake sediment cores, post-fire vegetation cohorts and land-surface models. Investigators have used synchronous patterns of postfire tree recruitment to reconstruct highseverity fire regimes in coastal temperate rainforest, boreal forest, and subalpine forests in British Columbia and Alberta; however, less is known about the history of low- and mixed-severity fire regimes. Recent research funded by the National Science and Engineering Research Coun- cil (NSERC) promises to improve this situation. For example, a network of 30 sites in the southern Rocky Mountain Trench shows highly variable fire-return intervals, some synchrony with regional fires in adjacent US states, and evidence of fire suppression over the $20^{\text {th }}$ century (Heyerdahl et al., 2008). Other research is developing regionally intensive networks of sediment cores, cohort data and fire scars in southeastern British Columbia.

In Mexico, the fire-history network includes over 25 georeferenced, cross-dated studies in northern Mexico (Fulé et al., 1997, 1999; Heyerdahl and Alvarado, 2003; Stephens et al., 2003). Many forests have experienced fire exclusion only recently or not at all, which allows for comparisons with adjacent US forests where fire has been suppressed for over a century (Stephens et al., 2008). Presence of $20^{\text {th }}$ century fire scars also allows for analysis of controls on fire occurrence using modern instrumental weather data and new insights into the influence of climate variation on fire, such as variation in ENSO teleconnections in space and time across the region (Yocom et al., 2010). 


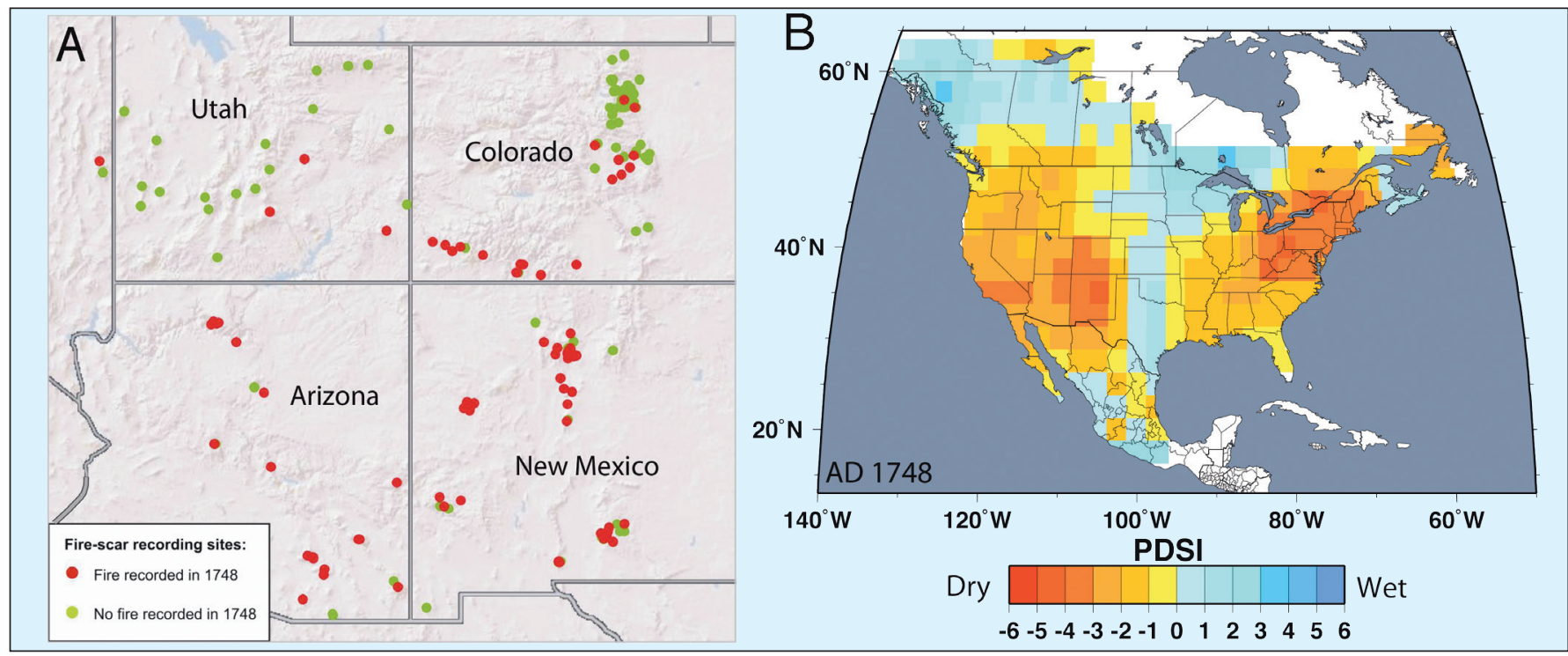

Figure 3: Synchronous fire occurrence captured in fire history networks can provide information on top-down fire controls. A) Regional fire patterns in AD 1748 across southwestern North America, a year of widespread fires in the region. Data from the International Multiproxy Paleofire Database (see Data section of text) and individual research studies. Map by E. Bigio, University of Arizona. B) Values in the Palmer Drought Severity Index (PDSI) for AD 1748 reconstructed from tree-ring width data (from Cook and Krusic, 2004).

\section{New directions}

The US Forest Service Global Change Research Program and the Joint Fire Science Program (JFSP) are supporting a new collaborative project, "Fire and Climate Synthesis" (FACS) to quantitatively synthesize fire climatology in western North America. Analogous efforts are underway in northern Mexico (National Science Foundation) and Canada (NSERC). We are employing multivariate similarity and cluster analysis techniques to create self-organizing maps of coherent fire-climate regions with persistent patterns of similarity in past fire. Regression and association tests (e.g., superposed epoch analyses) are used to infer the mechanisms of climate control of fire, including lagged climate effects. FACS emphasizes the role of annual-to-decadal climate variation that complement analyses of potential future climate variations on fire regimes (Brown et al., 2004; Flanigan et al., 2009).

Girardin et al., (2006) recently demonstrated an approach that enables the development of dendrochronological fire histories in regions or ecosystems lacking fire scars. Exploiting the strong control of climate on fire, they infer historical area burned in Canada using regression mod- els built from modern climate-sensitive ring-width chronologies and $20^{\text {th }}$ and $21^{\text {st }}$ century observations of area burned. This approach has significant potential because tree-ring chronologies remain more numerous and more widely distributed than the fire-scar data per se. Multi-proxy and modern fire history cross-calibrations, using combinations of ring-width, fire scar and area burned time series, offer the potential for centuries-long calibration and verification with independent records (Westerling and Swetnam, 2006). Enhanced multi-proxy and modern firehistory networks help reconstruct longterm estimates of area burned, biomass consumed and fire-carbon relationships (Hurteau et al., 2008) and provide a comparison with decadal- to centennial-resolution charcoal time series (e.g., Marlon et al., 2008). Fire-scar networks are also developing in Scandinavia, Russia, Mongolia and temperate South America, and combined with other proxies, will clarify the past, present and future role of fire in those regions.

\section{Data}

More than 480 fire-scar chronologies are archived in the International Multiproxy Paleofire
Database (http://www.ncdc.noaa.gov/paleo/ impd/paleofire.html) with an additional 500 chronologies yet to be archived (Falk et al., unpublished). Tree-ring data is available from the The International Tree-Ring Data Bank (http:// www.ncdc.noaa.gov/paleo/treering.html), and Palmer Drought Severity Index data is available at The North American Drought Atlas website http://iridl.Ideo.columbia.edu/SOURCES/. LDEO/.TRL/.NADA2004/.pdsi-atlas.html

\section{References}

Brown, P.M. and Wu, R., 2005: Climate and disturbance forcing of episodic tree recruitment in a southwestern ponderosa pine forest, Ecology, 86:3030-3038

Girardin M.P., Bergeron, Y., Tardif, J.C., Gauthier, S., Flannigan, M.D. and Mudelsee, M., 2006: A 229-year dendroclimatic-inferred record of forest fire activity for the Boreal Shield of Canada, International Journal of Wildland Fire, 15: 375-388.

Heyerdahl, E.K., McKenzie, D., Daniels, L.D., Hessl, A.E., Littell, J.S. and Mantua, N.J., 2008: Climate drivers of regionally synchronous fires in the inland northwest (1651-1900), International Journal of Wildland Fire, 17: 40-49.

Kitzberger T., Brown, P.M., Heyerdahl, E.K., Veblen, T.T. and Swetnam, T.W., 2007: Contingent Pacific-Atlantic Ocean influence on multi-century fire synchrony over western North America, Proceedings of the National Academy of Sciences USA, 104 543-548.

Yocom, L., Fulé, P.Z., Brown, P.M., Cerano, J., Villanueva-Díaz, J., Falk, D.A and Cornejo-Oviedo, E., 2010: El Niño-Southern Oscillation effect on a fire regime in northeastern Mexico has shifted over time, Ecology, 91: 1660-1671.

For full references please consult:

http://www.pages-igbp.org/products/newsletters/ref2010_2.html 